\title{
Perbedaan Efektifitas Masker Buff dan Masker Surgical untuk Mencegah Bakteri Menginfeksi Saluran Pernafasan Pengguna Motor di Jalan Daan Mogot
}

\author{
Maroloan Aruan ${ }^{1}$, Muhammad Rizky Khaerullah ${ }^{2}$, Stiya Prihatin ${ }^{2}$ \\ Teknologi Laboratorium Medis STIKes Kesetiakawanan Sosial Indonesia, Jakarta \\ Email: maroloanaruan@gmail.com
}

\begin{abstract}
Abstrak
Motor sebagai alat transportasi memiliki kelemahan, kurangnya perlindungan terhadap pernafasan dari kontaminasi bakteri udara. Penelitian ini bertujuan untuk melihat perbedaan efektifitas penggunaan masker Buff dan masker Surgical dalam menyaring bakteri. Penelitian ini menggunakan metode Eksperimental. Proses sampling dilakukan pada medium NA dengan cawan petri yang ditutup kain masker Buff dan masker Surgical. Isolat bakteri yang diperoleh dibiarkan tumbuh, lalu dihitung jumlah koloni bakteri pada masing-masing cawan petri setelah 24 jam. Dari hasil penelitian didapatkan hasil uji t-test dengan nilai $\alpha=0.000$ dimana nilai $\alpha<0.05$ : terdapat perbedaan efektifitas antara Masker Buff dan Masker Surgical dalam menyaring bakteri penyebab gangguan saluran pernafasan.
\end{abstract}

Kata kunci-Efektifitas, Masker, T-Test

\section{PENDAHULUAN}

Jakarta, Ibukota Negara Indonesia sebagai pusat bisnis dan pemerintahan menjadikan Jakarta sebagai daerah yang sibuk dan padat penduduk. Sebagai kota Metropolitan, dan memiliki jumlah penduduk yang tinggi mencapai sekitar 9.6 juta jiwa [1]. Hal ini dapat berdampak pada kondisi ibukota, salah satunya yakni tingkat kemacetan yang tinggi, sehingga masyarakat lebih memilih menggunakan motor sebagai alat transportasi sangat memudahkan warga untuk menghemat waktu jika dibandingkan dengan kendaraan lainnya. Namun, walaupun waktu tempuh motor lebih cepat, motor memiliki beberapa kelemahan Salah satunya adalah kurangnya perlindungan terhadap pengguna motor, terutama perlindungan terhadap pernafasan dari kontaminasi udara yang ditemui oleh pengendara di jalan terutama jalan yang berpotensi tinggi akan cemaran polutan, dan bioaerosol. Polusi udara memberikan dampak negatif terhadap kesehatan manusia seperti infeksi saluran pernafasan, kanker maupun jantung [2].

Untuk mencegah masuknya bakteri ke pernafasan saat menggunakan motor, masyarakat menggunakan alat pelindung pernapasan berupa masker pernafasan. Masker pernafasan merupakan alat yang berfungsi untuk melindungi organ pernapasan dengan menyalurkan udara bersih dan sehat dengan cara menyaring cemaran bahan kimia, mikroorganisme, partikel yang berupa debu, kabut (aerosol), uap, asap, gas/ fume, dan sebagainya yang masuk ke pernafasan [3].

Bakteri dapat ditemukan di jalanan yang padat dan penuh aktivitas. Beberapa studi menunjukkan kenaikan temperatur mempercepat pelepasan bakteri pada permukaan ke udara bersama dengan evaporasi. Kelembapan relatif yang tinggi akan melepas uap air ke udara sehingga sel viable dapat tumbuh dengan baik, tetapi kelembapan relatif yang rendah akan membantu bakteri endospora membentuk spora walaupun pada kondisi yang tidak baik sehingga keberlangsungan hidupnya lebih baik pada kondisi esktrem [4]. Hal ini dapat meningkatkan resiko bakteri dapat masuk ke dalam pernafasan jika tidak menggunakan alat pelindung berupa masker pernafasan yang baik.

Tidak semua masker dapat digunakan secara aman jika ditinjau dari segi kemampuannya untuk menyaring udara, terutama mencegah masuknya bakteri ke pernafasan. Ada berbagai macam masker pernafasan yang dapat digunakan oleh pemotor salah satunya yakni Masker Buff dan masker Surgical. Masker Buff yang memiliki pori-pori yang lebih besar jika dibandingkan dengan masker Surgical, sehingga masker Buff akan lebih sulit untuk mencegah bakteri masuk pernafasan. Masker Buff yang terbuat dari kain yang tidak dapat menyaring partikel-partikel yang terhembus oleh angin [5]. Hal ini tentunya akan meningkatkan resiko infeksi saluran pernafasan jika tidak menggunakan masker atau pelindung pernafasan yang kurang tepat. Namun masih banyak pengendara motor di Jakarta yang menggunakan masker tersebut. Berdasarkan latar belakang tersebut, peneliti bermaksud untuk melakukan penelitian yang bertujuan untuk melihat perbedaan efektifitas penggunaan masker Buff dan masker Surgical dalam mencegah Bakteri untuk menginfeksi saluran pernafasan pengguna motor di Jalan Daan Mogot. 


\section{METODE PENELITIAN}

Penelitian ini merupakan penelitian Eksperimental untuk melihat perbedaan perlakukan hasil filtrasi bakteri pada group perlakuan Masker Buff dan Masker Surgical yang dibandingkan dalam waktu yang bersamaan. Pengambilan sampel akan dilakukan pada bulan April 2019 di jalan raya Daan Mogot, Jakarta Barat untuk lokasi inkubasi dan pengamatan sampel berlangsung di Laboratorium uLab Kebon Jeruk Jakarta barat.

Nutrien Agar dibuat dengan menggunakan kombinasi bahan (Norris J. dan Ribbons D. 1970): 0,5\% Peptone, 0,3\% ekstrak daging sapi / ragi ekstrak, 1,5\% agar, 0,5\% Natrium Klorida, Air suling, lalu pH diatur ke netral (6.8) pada suhu $25^{\circ} \mathrm{C}\left(77^{\circ} \mathrm{F}\right)$. Bahan-bahan ini digabungkan dan direbus kira-kira satu menit untuk memastikannya tercampur dan kemudian disterilisasi dengan autoklaf, biasanya pada $121^{\circ} \mathrm{C}\left(250^{\circ} \mathrm{F}\right)$ selama 15 menit. Kemudian didinginkan hingga sekitar $50^{\circ} \mathrm{C}\left(122^{\circ} \mathrm{F}\right)$ dan dituangkan ke dalam cawan Petri yang tertutup segera. Setelah cawan petri berisi agar yang dipadatkan, disimpan dalam posisi terbalik dan didinginkan sampai digunakan.

Masker uji (Buff dan Surgical) yang telah distrerilisasi dimasukkan kedalam laminar airflow, buka penutup cawan petri dan pasangkan masing-masing masker uji pada media dan tutup kembali dengan penutup letakan dengan posisi terbalik, lakukan perlakuan yang sama pada semua cawan petri yang berisi media yang akan di uji. Setelah selesai berikan radiasi UV selama kurang lebih 15 menit, agar meminimalisir adanya kontaminasi media dan masker sebelum dilakukan inokulasi bakteri udara. Setelah diberikan paparan UV, dengan segera tempelkan media yang sudah ditutup masker diatas papan lebar (sejenis triplek dll) dan berikan perekat yang kuat agar media tidak jatuh atau terlepas.

Teknik isolasi bakteri mengikuti cara kerja Stryjakowska+-Sekulska dkk (2007) dengan beberapa penyesuaian [6]. Dilakukan modifikasi pada cawan petri dengan cara, cawan petri bagian atas dibuka lalu menutup cawan petri dengan masing-masing Masker Surgical dan Masker Buff, dengan 10 kali pengulangan lalu dilakukan pengulangan di jalanan Daan Mogot. Proses pengambilan sampel dilakukan selama 2 jam, selanjutnya, kain masker penutup dibuka, lalu ditutup dengan cawan petri, dan dikemas (sealed), lalu dibawa ke laboratorium untuk selanjutnya diinkubasi pada suhu 37 으 selama 24 jam lalu diamati.

\section{HASIL DAN PEMBAHASAN}

\section{Hasil Penelitian}

Pengambilan sampel dengan 10 kali pengulangan dimana 10 petri Masker Surgical dan 10 petri Masker Buff, telah didapati pertumbuhan bakteri setelah dilakukan inkubasi $1 \times 24$ dengan suhu $37^{\circ} \mathrm{C}$ dengan jumlah yang berbeda-beda pada setiap petri dan setiap jenis masker (Tabel 1 dan Gambar 1).

Tabel 1. Tabel perhitungan jumlah koloni masingmasing perlakuan antara masker buff dan masker surgical.

\begin{tabular}{|c|c|c|}
\hline \multirow{2}{*}{$\begin{array}{c}\text { Pengulangan } \\
\text { Ke- }\end{array}$} & \multicolumn{2}{|c|}{ Jumlah Koloni } \\
\cline { 2 - 3 } & $\begin{array}{c}\text { Masker } \\
\text { Surgical }\end{array}$ & $\begin{array}{c}\text { Masker } \\
\text { Buff }\end{array}$ \\
\hline 1 & 6 & 83 \\
\hline 2 & 9 & 53 \\
\hline 3 & 3 & 101 \\
\hline 4 & 7 & 68 \\
\hline 5 & 5 & 50 \\
\hline 6 & 6 & 70 \\
\hline 7 & 7 & 57 \\
\hline 8 & 4 & 58 \\
\hline 9 & 5 & 53 \\
\hline 10 & 7 & 99 \\
\hline
\end{tabular}

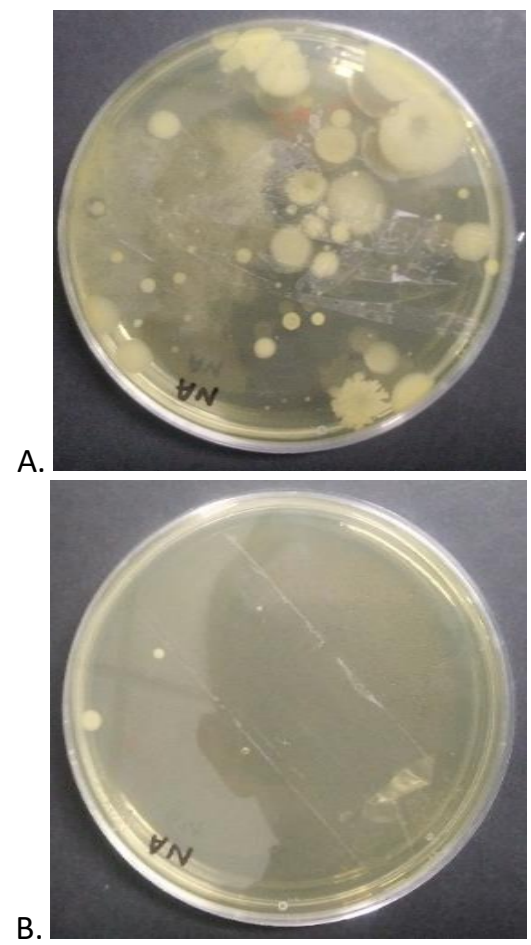

Gambar 1. Hasil kultivasi bakteri udara filtrat Masker Buff (A) dan Masker Surgical (B) pada salah satu 
Jurnal Biologi dan Pembelajarannya, Vol 7 No 1, April 2020. Pp: 15-18

e-ISSN: $2406-8659$

pengulangan media NA.

Sebelum melakukan uji Independent T-test perlu dilakukan uji homogenitas dan uji normalitas data. Berdasarkan perhitungan normalitas, didapatkan nilai Asymp. Sig $0.874>0.05$ pada Masker Surgical dan nilai Asymp. Sig $0.068>0.05$ pada Masker Buff sehingga dapat dinyatakan bahwa data berdistribusi normal, berdasarkan perhitungan homogenitas didapatkan nilai Signifikasi $0.000<0.050$, data dinyatakan tidak homogen. Setelah Uji Normalitas dan Homogenitas data telah dipenuhi maka dapat dilakukan uji Independent T-test (Tabel 2). Berdasarkan perhitungan T-Test, didapatkan hasil uji t-test dengan nilai $\alpha=0.000$ dimana nilai $\alpha<0.05$ sehingga ditentukan daerah penolakan yaitu pada Ho dan menerima H1, yang berarti terdapat perbedaan yang signifikan antara antara Masker Buff dan Masker Surgical dalam menyaring bakteri penyebab gangguan saluran pernafasan.

Tabel 2. Hasil Uji Independent T-test.

\begin{tabular}{|c|c|c|c|c|c|c|c|c|c|c|}
\hline & \multicolumn{2}{|c|}{$\begin{array}{l}\text { Levene's Test } \\
\text { for Equality } \\
\text { of Variances }\end{array}$} & \multicolumn{7}{|c|}{ t-test for Equality of Means } \\
\hline & & \multirow[t]{2}{*}{ F } & \multirow[t]{2}{*}{ Sig. } & \multirow[t]{2}{*}{$\mathrm{T}$} & \multirow[t]{2}{*}{ df } & \multirow{2}{*}{$\begin{array}{l}\text { Sig. } \\
(2- \\
\text { tailed) }\end{array}$} & \multirow{2}{*}{$\begin{array}{c}\text { Mean } \\
\text { Differenc } \\
\mathrm{e}\end{array}$} & \multirow{2}{*}{$\begin{array}{c}\text { Std. } \\
\text { Error } \\
\text { Differe } \\
\text { nce }\end{array}$} & \multicolumn{2}{|c|}{$\begin{array}{l}95 \% \text { Confidence } \\
\text { Interval of the } \\
\text { Difference }\end{array}$} \\
\hline & & & & & & & & & Lower & Upper \\
\hline $\begin{array}{l}\text { Hasil } \\
\text { Efekti } \\
\text { fitas }\end{array}$ & $\begin{array}{l}\text { Equal } \\
\text { variances } \\
\text { assumed } \\
\text { Equal } \\
\text { variances } \\
\text { not } \\
\text { assumed }\end{array}$ & 18.425 & .000 & -10.475 & 9.149 & .000 & -63.3000 & 6.0429 & $\begin{array}{l}-75.9957 \\
-76.9362\end{array}$ & -50.6043 \\
\hline
\end{tabular}

Pembahasan

Uji statistika menggunakan Independent T-test didapatkan hasil nilai signifikansi pada ( $\alpha$ ) t-test adalah 0.000 yakni lebih kecil dari 0.05 hal ini menunjukkan bahwa Ho ditolak dan H1 diterima, dengan demikian maka ada perbedaan efektifitas antara masker Buff dan masker Surgical dalam menyaring bakteri penyebab gangguan saluran pernafasan di Jalan Daan Mogot, Jakarta Barat. Hal ini disebabkan karena pori-pori yang terdapat pada Masker Surgical lebih efektif dalam mencegah penyebaran/ kontaminasi melalui mulut dan hidung secara langsung dari partikel bioaerosol. Masker Surgical diproduksi dari bahan polipropilena yang non-woven (tidak ditenun) dan terdiri atas satu lembar bahan penyaring yang memiliki beberapa lapisan atau layer sebagai pelindung untuk mencegah bakteri masuk pernafasan. Umumnya lapisan-lapisan ini mencakup lapisan antiair di bagian dalam dan lapisan thermobond di bagian terluar. Lapisan terdalam berfungsi untuk menahan cairan tubuh seperti keringat dan air liur agar tidak keluar dari dalam masker, sedangkan bagian luar masker berfungsi sebagai pertahanan pertama terhadap cairan kontaminan dari luar masker seperti darah. Masker ini digunakan oleh tenaga medis untuk menyaring tetesan air dan aerosol yang mengandung bakteribakteri patogen dari mulut dan hidung penggunanya agar tidak menyebar ke udara [8].

Hasil penelitian ini juga sesuai dengan penelitian Smith dkk. (2016) yang menyatakan bahwa masker Surgical setara dengan masker medis, masker prosedural, masker isolasi, masker laser, masker tahan cairan, dan masker wajah yang memenuhi standar efisiensi penyaringan bakteri dan partikel [9]. Masker Buff yang memiliki pori-pori yang lebih besar jika dibandingkan dengan masker Surgical, sehingga masker Buff akan lebih sulit untuk mencegah bakteri masuk pernafasan. Hal ini tentunya akan meningkatkan resiko infeksi saluran pernafasan jika tidak menggunakan masker atau pelindung pernafasan yang kurang tepat.

Masker Surgical sendiri lebih efektif dalam menyaring partikel bioaerosol karena sudah terstandarisasi oleh American Standard Testing and Material dalam menyaring bakteri dan pada udara. Di daerah dengan tingkat cemaran polutan dan bioaerosol yang tinggi seperti Jalan Daan Mogot penggunaan masker Surgical lebih efektif dalam menyaring bakteri penyebab gangguan saluran pernafasan daripada masker Buff. Melalui hasil penelitian ini peneliti menyarankan untuk tidak menggunakan masker Buff sebagai pelindung pernafasan saat berkendara motor. 
Jurnal Biologi dan Pembelajarannya, Vol 7 No 1, April 2020. Pp: 15-18

e-ISSN: $2406-8659$

\section{SIMPULAN}

Dari hasil penelitian didapatkan hasil uji t-test dengan nilai $\alpha=0.000$ dimana nilai $\alpha<0.05$, yang artinya terdapat perbedaan efektifitas antara Masker Buff dengan Masker Surgical dalam menyaring bakteri penyebab gangguan saluran pernafasan.

\section{SARAN}

\section{UCAPAN TERIMA KASIH}

Ucapan terima kasih kepada peyandang Yayasan STIKes Kesetiakawanan Sosial Indonesia, Jakarta, asisten peneliti Muhammad Rizky Khaerullah dan Stiya Prihatin.

\section{DAFTAR PUSTAKA}

[1] BPS. 2010. Jumlah dan Distribusi Penduduk. [Online] Diakses dari https://sp2010.bps. go.id/index.php/site?id=31\&wilayah=DKI-Jakarta pada tanggal 21 Juni 2019.

[2] Yusad, Yusniwarti. 2003. Polusi Udara di Kota-Kota Besar di Dunia. Fakultas Kesehatan Masyarakat USU. Medan.

[3] Health and Safety Authority. 2008. A Guide to Respiratory Protective Equipment.

[4] Lumoma, Sonja. 2016. Bakteriologi. Surabaya: R.A.De.Rozarie, 198-199.

[5] Cahyono, A. B. 2010. Keselamatan Kerja Bahan Kimia di Industri. Yogyakarta: Gadhjah Mada University Press.

[6] Stryjakowska-Sekulska, M dkk 2007. Microbiological Quality of Indoor Air in University Rooms. Polish Journal of Environments Study, 16: 623-632.

[7] Bayer, Robert T. 1998. Disposable Face Mask. [Online] http://www.freepatentsonline .com/5735270.pdf, diakses tanggal 22 Juli 2019.

[8] Smith, Jeffrey dkk. 2016. Effectiveness of N95 respirators versus surgical masks in protecting health care workers from acute respiratory infection: a systematic review and meta-analysis. Canadian Medical Association Journal.

[9] Norris J. dan Ribbons D. 1970. Methods in Microbiology. (Eds.1), Vol. 3A, Academic Press, London. 